\title{
JERÓNIMO ZURITA Y LA INQUISICIÓN: MEMORIALES AL REY (1572-1573)*
}

\author{
ISABEL EXTRAVÍS HERNÁNDEZ \\ Universidad de Zaragoza \\ extravis@unizar.es
}

\section{Resumen}

Cuando Jerónimo Zurita fue nombrado cronista del Reino de Aragón, en 1548, llevaba más de diez años prestando servicios a la Inquisición, y continuó haciéndolo hasta su muerte en 1580. Además, desde 1566 fue nombrado secretario de Felipe II para quien, gracias a su experiencia en el Santo Oficio y su buen hacer como historiador, preparó distintos memoriales. Los temas estaban relacionados, entre otros, con el nombramiento de inquisidor general, lugares de reunión del Consejo de la Inquisición o formas de proceder ante situaciones inesperadas, como la muerte del inquisidor general Pedro Ponce de León.

Analizaremos estos informes y la correspondencia mantenida referida a los mismos, entre Zurita y Felipe II, en el periodo comprendido desde la muerte del inquisidor general Diego de Espinosa y el nombramiento de Gaspar de Quiroga como su sucesor en el cargo.

Palabras clave: Zurita, Consejo de la Inquisición, inquisidor general, memorial, Felipe II, consejero, historiador.

\begin{abstract}
Jerónimo Zurita and the Inquisition: Memorials to the King (1572-1573)

When Jerónimo Zurita was appointed chronicler of Kingdom of Aragon, in 1548 already he had more than ten years providing services to the Inquisition and he continued to do it until his death in 1580. In addition, from 1566 he was appointed

\footnotetext{
* Este trabajo forma parte de los proyectos de investigación del Grupo de Investigación Consolidado Blancas de la Universidad de Zaragoza, financiado por el Gobierno de Aragón con fondos FEDER.
} 
Secretary of Felipe II for who, thanks to his experience in the Santo Oficio and his good do as historian, he prepared different memorials. The issues was, among others, with the appointment of General Inquisitor, meeting places for the Council of Inquisition or forms of behavior in unexpected situations, such as the death of general inquisitor Pedro Ponce de León.

We will analyse these reports and maintained correspondence referred to them, between Zurita and Felipe II, in the period from the death of the General Inquisitor Diego de Espinosa and the appointment of Gaspar de Quiroga as his successor in office.

Keywords: Zurita, Council of Inquisition, General Inquisitor, memorial, Felipe II, conselor, historian.

\section{Introducción}

En las Cortes de Monzón de 1547 se aprobó la creación del oficio de cronista para el reino de Aragón. El elegido debía de ser «una persona experta, sabia y próvida en corónicas e historias» y su trabajo consistiría en «escribir, recopilar y ordenar todas las cosas notables de Aragón, así pasadas como presentes» ${ }^{1}$. La persona escogida para desempeñar tan importante tarea fue Jerónimo Zurita (Zaragoza, 1512-1580), una elección acertada si nos atenemos a la crítica favorable, salvo contadas excepciones ${ }^{2}$, que sus Anales han recibido desde su publicación hasta nuestros días ${ }^{3}$.

El tiempo dedicado a la preparación y redacción de los treinta libros de Anales, y la repercusión que tuvieron, nos hacen olvidar, en ocasiones, el resto de su obra y, sobre todo, su trayectoria profesional al servicio del Santo Oficio y la Corona. Pero fue precisamente la coincidencia de su oficio como cronista

1. ANDRÉS DE UZTÁRROZ y DORMER, 1878: 121. A partir de ahora citaremos solo a Dormer cuando hablemos de sus autores, aun cuando la mayor parte de la obra está escrita por Juan Francisco Andrés de Uztárroz.

2. Las primeras y más duras fueron las planteadas por Lorenzo de Padilla y Alonso de Santa Cruz. En defensa de Zurita les contestaron Juan Páez de Castro y Ambrosio de Morales. ANDRÉS DE UZTÁRROZ y DORMER, 1878: 147-172.

3. Sobre las alabanzas que recibieron los Anales de Zurita, ANDRÉS DE UZTÁRROZ y DORMER, 1878, recogen una selección: 225-231 y 364-416. Sobre críticas actuales, un ejemplo: Lea escribe de Zurita que es «un hombre al que todos los españoles cultos deben gratitud», LEA, 1982: 61. REDONDO VEINTEMILLAS, 88 (2013): 12-18. 
y oficial del Santo Oficio lo que le permitió aportar una valiosa información a Felipe II, relativa al funcionamiento de una institución que conocía desde dentro y en profundidad, no solo por su trabajo, también por los muchos y variados informes que tuvo a su disposición.

Aunque la documentación inquisitorial relacionada con Zurita es muy amplia ${ }^{4}$, en este artículo trabajaremos con un número reducido de fuentes primarias. Son principalmente unos memoriales y billetes intercambiados entre Zurita y Felipe II, fechados entre septiembre de 1572 y mayo de 1573, referidos a temas directamente relacionados con la elección de un nuevo inquisidor general, tras la muerte de Diego de Espinosa.

Lo que pretendemos es, en primer lugar, aportar una imagen de Zurita algo más amplia que la de historiador. La de un hombre que llegó a conocer muy bien el funcionamiento del Santo Oficio por lo que pudo trasmitir al rey variada información sobre este tema. En segundo lugar, mostrar unos informes referidos a la administración de la Inquisición, en un momento especialmente complicado para la institución. Unos años con graves problemas económicos, tensiones internas y con su atención centrada en los herejes luteranos. Coincidiendo, además, con un periodo de cambios en el ámbito de la política ya que murieron o cayeron en desgracia los grandes «patrones» que habían encabezado los partidos «ebolista» y «albista»: Ruy Gómez de Silva y el duque de Alba. También fallecieron altos cargos de la monarquía, el cardenal Espinosa y el duque de Feria, pero no por ello acabaron las luchas por el poder de sus servidores, quienes controlaron la administración central durante el último cuarto de siglo ${ }^{5}$. Los nuevos partidos políticos pasaron a defender dos formas de entender la ideología católica: una hispanista o «castellanista», apadrinada por Mateo Vázquez, y otra partidaria de un catolicismo más universal, la «romanista» o «papista», defendida por otro secretario del rey, Antonio Pérez ${ }^{6}$.

4. Tanto la que se encuentra en la Real Academia de la Historia, Colección Salazar y Castro, como en Simancas, en el Archivo Histórico Nacional, sección Inquisición, y en el Archivo de la Diputación de Zaragoza, forman parte de lo que se conoce como Alacena de Zurita. Sobre su origen y destino: ANDRÉS DE UZTÁRROZ, DORMER, 1878: 149. DOMINGO MALVEDÍ, 2010: 41.

5. MARTÍNEZ Millán, 1992: 196

6. MARTínEZ MiLlán, 1994: 29. 
¿Es posible situar en uno de estos grupos a Zurita? Parece, por los documentos estudiados hasta el momento, que al menos en la elección del sucesor para el cargo de inquisidor general sí tenía claro las condiciones que debía reunir el elegido y que tanto Pedro Ponce de León como Quiroga eran personajes con quienes guardaba afinidad. De igual modo que es conocida la vinculación de este último con Ruy Gómez de Silva y Antonio Pérez, y por tanto con el partido «ebolista» ${ }^{7}$.

\section{Zurita ¿historiador - consejero ${ }^{8}$}

F. J. Andrés de Uztárroz en su obra Progresos de la Historia de Aragón y elogios de Gerónimo Zurita, su primer cronista llama la atención sobre cómo Zurita cumplió con el doble papel asignado a su trabajo como cronista: escribir las cosas del pasado y las del presente. El resultado de lo primero fueron sus Anales, de lo segundo, las consultas y memoriales relacionados sobre todo con su cargo de secretario de Felipe $\mathrm{II}^{9}$. Zurita fue un cronista para quien la Historia debía aportar:

Enseñanzas del pasado. Esta fue muy acatada entre todas gentes; porque siempre convino tener presente lo pasado y considerar con cuánta constancia se debe fundar una perpetua paz y concordia civil, pues no se puede ofrecer mayor peligro que la mudanza de los estados en la declinación de los tiempos. Teniendo en cuenta con esto, siendo todos los sucesos tan inciertos a todos y sabiendo cuan pequeñas ocasiones suelen ser causa de grandes mudanzas, el conocimiento de las cosas pasadas nos enseñará que tengamos por más dichoso y bienaventurado el estado presente, y que estemos siempre con recelo del que está por venir ${ }^{10}$.

Y para que las enseñanzas fueran las correctas, su obra siguió el método científico basado en la crítica histórica de los documentos, impulsada por Lorenzo Valla, para de esta forma:

[...] la verdad en todo sea preferida, que he sido, y soy muy notado en esto, y aun para decir a v.m. la verdad, reprehendido. Pero esto importa poco,

7. AVILÉS FERNÁNDEZ, 1 (1984a): 86.

8. Tomado de: KaGAN, 88 (2013): 199-210.

9. ANDRÉS DE UZTÁRROZ, DORMER, 1878: 121-124.

10. Preámbulo de ZuRITA, 2003: http://ifc.dpz.es/publicaciones/ebooks/id/2448, [consultado 15 de enero de 2014]. 
respeto de lo que se debe, porque sino se hubiera de tratar con la libertad que convenía, y se trasluce en esos libros que v.m. ha leído (la primera parte de los Anales), nunca yo me encargara de este oficio, que por esta causa es a muchos muy pesado, y odioso ${ }^{11}$.

En la misma carta, dirigida a don Fadrique Font y Pastor en respuesta a una suya en la que planteaba algunos reparos a los Anales ${ }^{12}$, Zurita insistía en cómo su trabajo se basaba en:

[...] poner la verdad en su lugar, pues a no tener esta en cuenta, podría yo ser notado de muy desatinado, y perdido, como el Pintor que se hubiese trabajado, y fatigado mucho en dejar de sus manos dibujada una pintura, sino en perfección, al menos en aquel punto que bastase toda su industria, y artificio, y después de tenerla acabada la ensuciase con barro, y la enlodase ${ }^{13}$.

Además de la crítica textual, Zurita fue innovador en la historiografía de su tiempo por el manejo directo de fuentes documentales y archivísticas y «la clara distinción de lo verosímil y lo inverosímil, lo legendario de lo real» ${ }^{14}$. Dando por ciertas sus cualidades como historiador ¿eran mérito suficiente para poder considerarle consejero del rey? El cronista era originariamente una persona que trabajaba en las cancillerías reales, lo que hoy denominaríamos un funcionario. Algunos de ellos preferían vivir alejados de la Corte para preparar sus obras, como fue el caso de Juan Ginés de Sepúlveda, Juan Páez de Castro o Justo Lipsio. Una decisión que iba en contra de la idea que tenía Antonio de Herrera de un buen historiador, ya que: «La buena historia, escribió, y sobre todo la historia que trataba de los asuntos contemporáneos, necesitaba un escritor experimentado en los asuntos de gobernar [...] y estar totalmente inmerso en la política y la vida cortesana ${ }^{15}$.

Un precepto que cumplió Zurita durante la mayor parte de su vida profesional, pues aun cuando hubo periodos que por su trabajo estuvo ausente de la Corte, las tareas que estaba realizando le proporcionaban información

11. ANDRÉS DE UZTÁRROZ y DORMER, 1878: 583.

12. Real Academia de la Historia [RAH], Colección Salazar y Castro [CSC], A/112, f. 712 y 713. ANDRÉS DE UZTÁRROZ y DORMER, 1878: 582-3.

13. Ibidem, f. 214. Ibidem: 584. La carta esta fechada en Zaragoza a 11 de marzo de 1563. 14. SARASA SÁNCHEZ, 88 (2013): 61.

15. KAGAN, 88 (2013): 208. 
de primera mano sobre cuestiones relacionadas con la misma ${ }^{16}$.Sin olvidar la amplia y variada correspondencia que mantuvo con humanistas, oficiales de la Inquisición o miembros de la administración destinados en Italia, Flandes, Francia o Inglaterra que le mantenían al día de los últimos acontecimientos del ámbito político, cultural y religioso ${ }^{17}$.

Sus cualidades como historiador le capacitaban como un buen candidato para ejercer de consejero del monarca en temas relacionados con la Historia, algo de lo que tenemos constancia ${ }^{18}$. Pero su carrera profesional dentro del Santo Oficio le dotaban, también, de la experiencia necesaria para que la temática sobre la que podía proporcionar una información valiosa al rey fuera mucho más amplia, como veremos.

\section{Zurita en la Inquisición}

En las capitulaciones matrimoniales de Jerónimo Zurita y Juana García de Oliván, firmadas en Valladolid el 31 de diciembre de 1537, las principales aportaciones de los novios al matrimonio eran cargos. Por parte de Zurita, la bailía de Huesca, el merindazgo de Huesca, de Barbastro, de Sariñena y de Almudévar, «los cuales oficios tiene de por vida». El padre de la novia, por su parte, aportaba el cargo de secretario de la Inquisición para ejercerlo entre ambos, con la condición de que el salario (1.100 ducados) y ayudas correspondientes a dicho oficio le fueran pagados a Juan García hasta su muerte. Como testigo de estas capitulaciones figura Alonso Manrique, «cardenal de los doce apóstoles y arzobispo de Sevilla, inquisidor general contra la apostasía y la herejía» quien concede la petición de Juan de nombrar a su

16. Alguna de las órdenes que recibió para recoger documentación de archivos o particulares por orden del rey o de la Inquisición figuran en los siguientes documentos: RAH, CSC, A/111, f. 159, 160, 161, 162, 357, 358. También encontramos referencias a dichas solicitudes en ANDRÉS DE UZTÁRROZ y DORMER, 1878: 88.

17. La que mantuvieron con Jerónimo Zurita, Gonzalo Argote de Molina, Antonio Agustín, Hernán Núñez de Guzmán, Juan Páez de Castro y Juan de Verzosa está publicada. En Progresos aparecen además una variada muestra de la correspondencia de Zurita con un gran número de personajes de la época.

18. RAH, CSC, R/63, f. 84 y 87. ANDRÉS DE UZTÁRROZ y DORMER, 1878:120-124. 
yerno coadjutor de su oficio, por la enfermedad que le impide ejercer como secretario y para que sea titular a su muerte ${ }^{19}$.

El decreto con el nombramiento de secretario coadjutor para Zurita se firmó el 18 de diciembre de $1536^{20}$, por lo que a la firma de los capítulos matrimoniales, y dada la enfermedad de Juan García, ya llevaba ejerciendo el oficio un año ${ }^{21}$. Sabemos que en la villa de Valladolid a 20 de noviembre de 1536 hicieron testamento sus suegros. Y que en Sevilla, a 30 de abril de 1538, el inquisidor Alonso Manrique dio provisión para que se le redimieran a la viuda de Juan García 700 escudos que su marido había recibido para gastos en el Consejo ${ }^{22}$. Según estos datos, Zurita ejerció de facto como secretario del Consejo de la Inquisición para Aragón desde su nombramiento en diciembre de 1536 hasta, aproximadamente, dos años después cuando fallecería su suegro, y como titular desde entonces ${ }^{23}$. Fue sustituido en 1548 por Juan de Valdés, sobrino del nuevo inquisidor general.

No parece haber duda sobre la importancia de los secretarios del Consejo, pero para José Antonio Escudero, al tener estas secretarías un carácter cerrado y no servir como trampolín para acceder a otras de Consejos de Estado, sus titulares carecían de fama ${ }^{24}$. Aun sin contar con este reconocimiento público, el secretario debía ser cuidadoso en los detalles de los negocios que trataba y con experiencia para conocer los asuntos en que trabajaba, intentando evitar errores $^{25}$. Saavedra Fajardo escribía sobre ellos que «puede gobernarse un príncipe con malos Ministros, pero no con un Secretario inexperto [...] Mírense bien los tiempos pasados, y ningún estado se hallará bien gobernado,

19. RAH, CSC, A/110, f. 80 y 81.

20. Los secretarios coadjutores eran los encargados de sustituir a los secretarios propietarios cuando estos no asistían a los Consejos. ESCUDERO, 14 (1987): 76.

21. RAH, CSC, A/111, f. 52-53.

22. Por un escrito -sin fecha- de Jerónimo Zurita de Oliván que envió a Felipe III sobre su limpieza de sangre y notas genealógicas, RAH, CSC, A/110, f. 337-341.

23. El cargo de secretario de Juan García era para el Consejo de la Inquisición de Aragón, Navarra e Indias, que se ocupaba de los tribunales de Zaragoza, Barcelona, Valencia, Logroño, Sicilia, Mallorca, Cerdeña, México, Lima y Cartagena de Indias. Tomó posesión del mismo en 1513 y lo ejerció, como hemos visto, hasta su muerte en 1538. ESCUDERO, 14 (1987): 76-77.

24. Ibidem: 78.

25. LÓPEZ VELA, 1993b: 731. 
sino aquel en el que hubo grandes Secretarios», aunque no se refería específicamente a los secretarios del Consejo ${ }^{26}$.

Esta forma de cesión de cargos, como si fueran propiedad de los titulares - cosa que no era cierta- era propia de una administración del Estado en la que los oficiales no eran elegidos, o no únicamente, por su capacidad para desempeñarlos, sino por su pertenencia a un grupo dirigente $e^{27}$. Tanto la familia Zurita como la de su mujer eran aragoneses, prestaron servicios a Fernando el Católico y a su nieto Carlos $\mathrm{V}^{28}$ y si, como hemos visto, Zurita accedió a la Inquisición gracias a su matrimonio, algo similar debió de suceder en el caso de su suegro ${ }^{29}$.

En 1548 Zurita fue relevado como secretario del Consejo de la Inquisición y nombrado cronista oficial del reino de Aragón. Ese mismo año murió su mujer y se trasladó desde Valladolid a Zaragoza. En 1549, el 17 de enero, recibió el nombramiento como contador de la Inquisición, según consta en una cédula de Maximiliano y María de Austria. El salario de este oficio era de doscientos ducados al año ${ }^{30}$. Fue el encargado de controlar las cuentas de

26. SAAVEDRA FAJARDO, 1801: 62.

27. MARTínEZ Millán, 1994: 17.

28. Para más información sobre la genealogía de Zurita y los cargos desempeñados por los miembros de su familia: ANDRÉS DE UZTÁRROZ y DORMER, 1878: 7-50; un resumen de estos datos en EXTRAVís HeRnÁndeZ, 2014: 32-42.

29. Tres de sus cuñados fueron: Martín de Oliván, abad de san Juan de la Peña e inquisidor de Calahorra y Córdoba; Miguel, secretario de la Inquisición; Margarita, casada con el receptor de la Inquisición en Valencia. También un tío de su mujer, Agustín de Oliván, fue teólogo de la Inquisición.RAH, CSC, A/110, f. 411-8. Es un manuscrito sin fecha con la descendencia de Juan de Oliván, el mayor, hasta su tercer nieto, Jerónimo Zurita de Oliván y de sus apellidos Oliván, Yziz y García.

Lea también hace referencia a un Jerónimo Zurita, secretario de la Suprema en 1519, que probablemente fuera tío del historiador. LEA, 1982: 61.

30. Por su trabajo recibió en enero de 1550 , por orden del inquisidor general, Fernando de Valdés, ciento cincuenta ducados de ayuda de costa por haber puesto en orden los libros de la hacienda de los tribunales de Aragón. RAH, CSC, A/111, f. 44. Diez días más tarde, en dos cédulas firmadas también por Maximiliano y María de Austria, y dirigidas a los receptores de la Inquisición de Valencia y Barcelona, se ordenaba el pago a Zurita, como parte de su salario, de mil trescientos y de mil sueldos jaqueses, respectivamente. En la misma fecha, dos cédulas, con el mismo texto y dirigidas al receptor de la Inquisición de Zaragoza, ordenaban el pago a Zurita de mil sueldos jaqueses, como parte de su sueldo, y de cincuenta sueldos de oro anuales, como ayuda de costas. RAH, CSC, A/111, f. 46, 48, 50. 
Aragón, Cataluña, Valencia, Sicilia, Cerdeña y Mallorca hasta el año 1566. Durante ese periodo reformó la gestión de la hacienda inquisitorial con medidas de carácter administrativo, de control e investigando casos de receptores que habían ocultado o escamoteado ingresos del Tribunal del Santo Oficio ${ }^{31}$.

Su sucesor en el cargo estaba previsto que fuera su hijo mayor, Miguel, para quien solicitó el nombramiento de coadjutor suyo en 1560. Aunque la petición fue aprobada, el cargo debió quedar vacante cuando Miguel ingresó en la abadía de Porta Celi de Valencia, ya que finalmente fue Pedro de Heredia quien sustituyó a Zurita en enero de $1567^{32}$.

Es posible que el cese como contador del Santo Oficio para la Corona de Aragón se produjese como consecuencia del nombramiento de secretario de Cámara de Felipe II. Fue el 12 de diciembre de1566, con un salario de cien mil maravedíes ${ }^{33}$, y el 30 de marzo de 1568 fue designado sucesor de Lope Díaz de Zárate, para atender los asuntos del Consejo de la Inquisición, según la siguiente cédula:

Por cuanto los del nuestro Consejo de la General, y Santa Inquisición me han hecho saber, que por la muerte de Lope Díaz de Zárate, que tenía título y cargo de ello, les falta persona que como nuestro Escribano de Cámara refrende las provisiones patentes que por el dicho nuestro Consejo se despachan en nuestro nombre. Por la presente doy licencia y facultad a vos Jerónimo Zorita, Secretario que sois de dicho Consejo de la General Inquisición, para que como nuestro Escribano de Cámara podáis refrendar todas las dichas provisiones que así se despacharen en nuestro nombre por el dicho Consejo General de la Inquisición, ni que por ello se os pueda imputar cargo ni culpa alguna. En Barcelona a treinta días del mes de Marzo de $1568^{34}$.

El nombramiento fue ratificado el 17 de septiembre del mismo año por el inquisidor general, Diego de Espinosa ${ }^{35}$. Para sucederle en el cargo, Zurita intentó que fuera de nuevo uno de sus hijos, en este caso el menor, Jerónimo, aunque no era el único candidato, ya que Mateo Vázquez también aspiraba a

31. MARTínez MiLlÁN, 1993: 895.

32. Ibidem.

33. Dormer transcribe la real cédula con el nombramiento. ANDRÉS DE UZTÁRROZ y DORMER, 1878: 95-97.

34. RAH, CSC, A/111, f. 37. Ibidem: 656. Dormer fecha esta cédula en 1538, emitida por el Emperador, pero debe ser un error del escribano pues el nombramiento es de 1568 .

35. Ibidem: 97-98. 
ocuparlo. El valedor de Zurita en esta disputa fue el recién nombrado inquisidor general Gaspar de Quiroga, que intentaba hacer ver a Felipe II cómo las muchas ocupaciones de Vázquez le hacían incapaz de cumplir con las necesidades inherentes al cargo ${ }^{36}$. La caída en desgracia de Antonio Pérez en 1580 arrastró a Quiroga, quedando relegado a su cargo como arzobispo de Toledo, lo que unido a la muerte de Zurita en noviembre de ese mismo año, supuso que Mateo Vázquez lograra la secretaría del Consejo de la Inquisición.

Como vemos, el currículum de Zurita en el Santo Oficio fue extenso y variado. Además, hemos de tener en cuenta que durante estos años manejó muchísima información relativa a la Inquisición: funcionamiento, oficiales y hacienda. Sin olvidar, que se encargó de recoger la documentación que seguía en posesión de familiares de oficiales ya fallecidos ${ }^{37}$. Algo que probablemente sucedió con la de su suegro, que Zurita seguramente «heredaría» tras su fallecimiento, y que pudo estar entre la que hacía constar en su testamento con instrucciones para que fuera entregada al Santo Oficio ${ }^{38}$.

Aun cuando la documentación de Zurita, tanto la personal como la referente a sus cargos como secretario del rey o al servicio de la Inquisición, ha tenido un recorrido muy accidentado y una parte importante se ha perdido ${ }^{39}$, contamos con un fondo en la Colección Salazar y Castro de la Real Academia de la Historia que nos permite conocer escritos de gran valor como los tratados a continuación.

\section{La elección del inquisidor general}

El 5 de septiembre de 1572 moría el inquisidor general Diego de Espinosa. De esa misma fecha hay tres billetes intercambiados entre Zurita y el rey referentes a la elección del sucesor. En el que parece ser el primero, Zurita le

36. PizARro Llorente, 2004: 432.

37. En 1547, cuando Fernando de Valdés -arzobispo de Sevilla- tomó posesión del cargo de inquisidor general, dispuso que Zurita inventariase y recogiese todas las bulas, breves y documentos relativos al Santo Oficio que estuviesen en poder de los secretarios de Fernando el Católico, Juan Ruíz de Calcena y Hugo de Urriés para depositarlas en el Tribunal del Santo Oficio de Aragón. ANDRÉS DE UZTÁRROZ y DORMER, 1878: 56.LEA, 1982: 115.

38. Canellas lópez, X (1933): 1-22.Domingo Malvedí, 2010: 32.

39. Ver nota 4. EXTRAVÍS HERNÁNDEZ, 2014: 98-99. 
escribe a Felipe II sobre cómo continuará el Consejo de la Inquisición con sus funciones, si bien no podrá nombrar inquisidores y deberá reunirse en una iglesia hasta el nombramiento del nuevo inquisidor general. En el mismo billete el rey le contesta agradeciendo su desvelo, además acuerda tratar sobre ese tema la semana siguiente y añade que «no será malo tengáis mirado y me advirtáis y mostréis en qué forma será la nominación de inquisidor general» ${ }^{40}$.

No obstante, Zurita entregó al rey otro billete ese mismo día 5 en el que podemos leer: «Treinta y seis años ha que sirvo en las cosas secretas del Santo Oficio y he alcanzado siendo oficial en ellas cinco inquisidores generales -y tengo alguna noticia de los más antiguos- y nunca hubo desde que se fundó [e] instituyó tanta necesidad de proveer de dueño a las cosas de la Inquisición sin dilación que ahora ${ }^{41}$.

El vacío de poder en la dirección del Santo Oficio es una situación que Zurita había conocido con anterioridad. Transcurrieron veinte meses desde el nombramiento de Adriano como papa y la elección de su sucesor en la presidencia de la Suprema, Manrique. Un año desde la muerte de este hasta el nombramiento de Tavera y seis meses desde su óbito hasta que Loaisa tomó posesión de su cargo ${ }^{42}$. Quizás esa necesidad que plantea Zurita hizo que en esta ocasión el sucesor de Espinosa se eligiera con rapidez.

Más adelante recuerda al rey, cómo los Reyes Católicos tenían cuidado de no dejar vacante el puesto, incluso nombrando un nuevo inquisidor si el anterior no podía ejercer el cargo por enfermedad ${ }^{43}$. También hace memoria de las bondades del cardenal Alonso Manrique «que fue un excelente ministro en este cargo» y, aun reconociendo que siendo «Criado de V. M.,[estar]a su servicio me hace pasar delante de lo que por ventura se permite a un hombre de tan pocas prendas como yo», aconseja a Pedro Ponce de León, obispo de Plasencia, para el cargo de inquisidor general. De él dice que ya sirvió en el Consejo de la Inquisición, es «hechura de V. M.»y, dada su experiencia

40. RAH, CSC, R/63, f. 125. ANDRÉS DE UZTÁRROZ y DORMER, 1878: 125.

41. Ibidem, f. 123. Ibidem, p. 126.

42. GONZÁleZ NOVALÍN, 1984: 539.

43. Acompañaba a este billete una disposición de Inocencio VIII por la que autorizaba el nombramiento de sustituto para Torquemada por enfermedad. 
como jurista, le capacita mejor que un teólogo para ejercer como inquisidor general $^{44}$.

La misma premura de Zurita para informar al rey, la muestra Felipe II para responder ese mismo día (5 de septiembre de 1572) agradeciéndole el billete, e indicándole que si se «os ofrece otra cosa de que advertirme yo holgaré que lo hagáis». También le pide que mande cartas a los miembros del Consejo para que se reúnan, dónde deben hacerlo y lo conveniente que sería aprobarlo ese mismo día. Por último, hace mención al obispo de Segovia (Diego de Covarrubias, que sustituyó a Espinosa en el Consejo de Castilla) que debe ser informado y a quien «no habrá duelo que sino decírselo vos ${ }^{45}$.

Ponce de León estudió cánones en Salamanca, fue nombrado consejero de la Inquisición en 1546 y obispo de Ciudad Rodrigo. Relevado del Consejo de la Suprema cuando Valdés fue elegido inquisidor general y apartado de la Corte, participó en el Concilio de Trento y en 1559 fue nombrado obispo de Plasencia ${ }^{46}$. Antiguo servidor del inquisidor Tavera, formaba parte del partido «ebolista». Fue elegido inquisidor general en octubre de 1572, pero la bula papal con el nombramiento no se firmó hasta el 2 de diciembre y llegó a Madrid el 21 de enero de 1573, cuatro días después de su fallecimiento, por lo que no llegó a tomar posesión del cargo ${ }^{47}$.

En octubre de 1572 Zurita preparó un memorial dirigido a «(S.C.R.

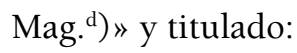

Obedeciendo el mandamiento de V. Mag., hace relación en este memorial de las cosas que yo entiendo que cumple al sujeto de Nuestro Señor y suyo, que tenga sabidas, y esté de ellas advertido, por la buena dirección de las causas y negocios del Santo Oficio, y para el buen regimiento y gobiernos de las Inquisiciones ${ }^{48}$.

El texto sigue con los dos poderes que tienen el Consejo y el inquisidor general: uno apostólico para las causas de la fe y otro real, para los asuntos civiles que resultan de los bienes confiscados a la Cámara y fisco real.

44. RAH, CSC, R/63, f. 123. ANDRÉS DE UZTÁRROZ y DORMER, 1878: 126.

45. Ibidem, f. 124. Ibídem: 127.

46. PINTO CRESPO, 1984: 769.

47. Zurita avisó al rey sobre la conveniencia de no hacer público el nombramiento antes de que el Papa firmase el breve. RAH, CSC, R/63, f. 124. PiZARro LlOREnTE, 2004: 227.

48. RAH, CSC, R/63, f. 126. Todo el párrafo está tachado. 
Continúa explicando cómo el inquisidor general es elegido tras la nominación hecha por el rey al papa quien, tras aceptarla, envía un breve confirmando la comisión en las mismas condiciones que su antecesor. Tras recibir el visto bueno el rey desde Roma, se nombra al nuevo inquisidor general y se le presenta ante el Consejo. Recuerda Zurita al rey dónde han tenido su posada los inquisidores Tavera, Loaisa y Valdés; la posibilidad que tuvieron los Reyes Católicos o Carlos V para nombrar sustituto en caso de ausencia prolongada o incapacidad del inquisidor general, caso de Adriano o de Valdés ${ }^{49}$.

La opción de nombrar a un sustituto que plantea Zurita, no impidió que hubiese largos periodos sin nadie que ejerciese el cargo, como hemos visto. Aunque tanto el nombramiento como la destitución del inquisidor general eran competencia pontificia, en la práctica, la persona elegida era la propuesta por el rey. Si bien esta facultad real nunca fue reconocida por la Santa Sede, haciendo hincapié, así mismo, en cómo no se hacía mención en el breve a petición alguna por parte del monarca ${ }^{50}$.

Después de lo que podemos considerar una aproximación histórica, Zurita no duda en intercalar un párrafo en el que plantea una propuesta propia sobre uno de los requisitos que debería cumplir un inquisidor general: no presidir otros consejos o comisiones, ya que sería un «gran inconveniente». Las razones que da Zurita son, por un lado, que no podría asistir a todas las reuniones del Consejo de la Inquisición y, por otro, que en caso de su muerte «no se puede decir que se pierde un ministro, sino muchos ministros ${ }^{51}$.

En este memorial Zurita repite la información que ya aportaba en el billete del 5 de septiembre que hemos visto: que la muerte del inquisidor general no suponía la paralización de las tareas del Consejo de la Inquisición y solo la posibilidad de nombrar inquisidores quedaba detenida. Esta afirmación de Zurita choca con estudios actuales que plantean la falta de legitimidad del

49. Ibídem.

50. LEA, 1982: 347.

51. RAH, CSC, R/63, f. 126v. De opinión contraria era Juan de Ovando, quien preparó en febrero de 1573 un informe para el monarca en el que destacaba lo beneficioso que sería que el inquisidor general fuera, al mismo tiempo, presidente del Consejo de Castilla. Planteaba como candidatos a Pedro de Deza, Diego de Covarrubias o él mismo, todos pertenecientes al partido castellanista. PIZARRO LLORENTE, 2004:228-229. 
Consejo en esa situación. No en cuestiones de justicia, sino de gracia, que correspondía exclusivamente al inquisidor general ${ }^{52}$.

El informe sigue con la forma de elección de funcionarios inquisitoriales:

Cuanto a la provisión de los oficios, en tiempos de los Reyes Católicos no se proveía ninguno sin consulta de sus Altezas: y así eran las consultas muy ordinarias. Y después, en tiempo del Emperador nuestro señor, cómo fueron restando [consultas al monarca] paso a paso, de muchos años atrás los inquisidores generales. [Estos] fueron proveyendo las plazas de los inquisidores, todas las otras de los oficiales del consejo y de las Inquisiciones, no solo sin consulta Real, [sino que también] en tiempo de Valdés y Espinosa, las más veces sin sabiduría del consejo y hasta sin recibir la información de su linaje, en [lo] que no deja de haber inconveniente ${ }^{53}$.

Para conocer las competencias en materia de nombramientos, los inquisidores generales contaban con el breve de Sixto IV que ordenaba que para proveer los distintos oficios, debían contar con personas «doctas y de buen ejemplo fama y costumbres $»^{54}$. La edad mínima para acceder a un cargo del Tribunal parece que era de 19 ó 20 años y, además, debían tener filiación legítima. En cuanto al control de la vida privada, a pesar de existir una fiscalización rígida, las malas costumbres eran frecuentes ${ }^{55}$. Además, el nepotismo y la trasmisión hereditaria de algunos oficios se manifestó pronto y estuvo generalizada. Las Instrucciones de 1498 prohibían el nombramiento de un familiar o criado de los inquisidores o de cualquier otro oficial para cualquier tribunal. Pero «tan normal llegó a ser esta conducta de la Inquisición que, cuando moría un oficial dejando un hijo menor, el puesto se cubría temporalmente hasta que se hiciese adulto» y pudiese sustituir a su padre ${ }^{56}$. Una práctica que Zurita conocía bien por haberse beneficiado de ella, como hemos visto.

Por lo que se refiere a la limpieza de sangre, era un requisito previo desde mediados de siglo para acceder a un oficio inquisitorial. Había dos clases de pruebas: las de oficial, para cargos de inquisidores y oficiales, y

52. Ver nota 40. LÓPEZ VELA, 1993a: 95.

53. RAH, CSC, R/63, f. 127.

54. BARRIOS PINTADO, 1 (1991): 131.

55. GARCía CÁRCEL, 1984: 420.

56. LEA, 1982: 79.

Revista de Historia Moderna, n. ${ }^{\circ} 35$ (2017) (pp. 439-466) | ISSN-e: 1989-9823 | ISSN: 0212-5862 
las de miembros de la organización de distrito. Las primeras las realizaban un secretario del secreto y un comisario, y las segundas un notario y un comisario. En ambos casos era condición necesaria pasarlas para acceder al cargo, aunque los criterios para los oficiales de la organización de distrito eran menos rigurosos ${ }^{57}$.

Zurita contrapone en este memorial la época inicial de la Inquisición con la que se vivía en esos momentos, en los que con la herejía luterana se había transformado la imagen de la institución, al considerarse todo el pueblo como posible sospechoso:

Porque nunca hubo tanta necesidad de mirar en las provisiones que se hubieren de hacer. Pues en los tiempos pasados, cuando la Inquisición era recién instituida, pareciese que toda la institución se empleaba contra el judaísmo y contra los sospechosos en él, y toda la gente noble y limpia hacían gran fuerza en favorecerla ${ }^{58}$.

Debido a este cambio, Zurita plantea la necesidad de que el Santo Oficio cuente con el apoyo del rey y, a la vez, se muestre honesto en su actuación. Porque, expone, en el «tribunal del mundo se hace necesidad de la Justicia en él» y especialmente el inquisidor general, que siempre había sido persona de «tanta autoridad y rectitud» para cumplir con su servicio.

Efectivamente, hasta mediados de siglo la Inquisición había perseguido básicamente a los conversos, «un problema más social que político, en que la beligerancia inquisitorial venía dada por los intereses sectoriales de la burguesía cristiano-vieja». Una situación que cambió con Valdés, quien involucró al alto clero y a la Corte en su lucha contra el luteranismo ${ }^{59}$. Aunque, si bien ha sido Valdés quien ha pasado a la Historia como el impulsor de la intransigencia religiosa, fue Espinosa quien puso en marcha las medidas para llevar adelante el ideario de la Contrarreforma ${ }^{60}$.

El memorial retoma el tema del nombramiento de oficiales del Consejo y la Inquisición. Explica que, en tiempos de Valdés, el fiscal, notarios, contador general, portero, relatores y secretarios, eran criados suyos y utilizaba estos

57. LÓPEZ VELA, 1993b: 679.

58. RAH, CSC, R/63, f. 127.

59. García Cárcel y Moreno Martínez, 2000: 63.

60. PizARRo LlORENTE, 1992: 239.

Revista de Historia Moderna, n. ${ }^{\circ} 35$ (2017) (pp. 439-466) | ISSN-e: 1989-9823 | ISSN: 0212-5862 
nombramientos para agradecer los servicios prestados. Y lo que Zurita considera peor: sus salarios se pagaban con las confiscaciones a los acusados por la Inquisición. Propone que los cargos de receptores y contadores requieran del poder y título real y se provean, al menos, tras una consulta al monarca.

La crítica de Zurita sobre el nepotismo de Valdés está plenamente justificada $^{61}$. Del nombramiento de familiares y clientes en cargos del Santo Oficio del inquisidor general fue, como hemos visto, el propio Zurita uno de los damnificados. Esta concentración de poderes era posible porque «sin instrucciones u ordenanzas que regulen con precisión la jurisdicción y competencias de cada una de las partes» -Consejo e inquisidor general- ${ }^{62}$, no existía más normativa referida a sus atribuciones que la recogida en el breve papal de su nombramiento y la bula de Sixto IV, ya mencionada. Entre las facultades con las que contaba desde su inicio, estaba la de elegir de manera unipersonal a los funcionarios inquisitoriales y fiscalizar su actuación. Solamente los consejeros eran elegidos por el monarca entre una terna presentada por el inquisidor general ${ }^{63}$. Existía, a la hora de elegir a los oficiales inquisitoriales, una justicia distributiva, de tal forma que el inquisidor general se rodeaba de personas de su confianza, pero al mismo tiempo tenía que ofrecerles una vía de promoción ${ }^{64}$.

Por lo que se refiere a las confiscaciones a las que hace referencia Zurita, ya desde su fundación la Inquisición debía ser autosuficiente y la base de su sostenimiento fueron las incautaciones. Teniendo en cuenta que tanto judíos como conversos poseían grandes capitales, «con la expulsión de los primeros y la persecución de los últimos, todos se vieron privados de esa riqueza» ${ }^{65}$. El sistema estaba perfectamente organizado, llegando hasta aprovecharse del miedo a la muerte próxima de quienes iban a ser ejecutados: sus confesores les exigían que detallaran todos aquellos bienes que hubiesen escapado a la investigación previa ${ }^{66}$.

61. Ibidem: 231-239.

62. LÓPEZ VELA, 1993a: 76.

63. Ibidem: 79.

64. LÓPEZ VELA, 1993b: 700.

65. LEA, 1982: 189.

66. Ibidem: 195. 
En su memorial, Zurita retoma el tema de la elección de inquisidor general, que debía recaer en «personas graves, de letras y de buen ejemplo de vida como se hizo en tiempo del arzobispo de Sevilla, Alonso de Manrique, y también con Adriano, Cisneros y Deza». Estas elecciones fueron fáciles durante los reinados de los Reyes Católicos y del emperador. Una de las cualidades que para Zurita debía cumplir el inquisidor general era la de contar con una renta mayor que la que le pudiera aportar este nombramiento, para así poder tener libertad para ejercer sin presiones económicas el cargo. Además, debería consultar con el rey los problemas derivados del gobierno del Consejo y de la Inquisición ${ }^{67}$.

Un estudio sociológico de los inquisidores generales, desde su origen hasta que Zurita prepara su memorial, nos muestra rasgos comunes como la pertenencia a familias de la nobleza y de cristianos viejos (excepto Torquemada, a quien algunos autores consideran de origen converso); con parientes o amigos en la prelacía o magistratura (Alonso Manrique y su hijo Jerónimo o Deza y su sobrino Tavera); con estudios superiores en una universidad, especialmente en Derecho. Existen también diferencias: hasta la llegada de Carlos $\mathrm{V}$, el cargo lo ejercieron miembros de órdenes mendicantes. Después, salvo el dominico Loaisa, todos los demás pertenecían al clero secular. También podemos marcar el reinado de Carlos V como límite para comprobar que el generalato inquisitorial fue la última dignidad de relieve, a diferencia de Espinosa y Quiroga, cuyos grandes cargos eclesiásticos fueron posteriores a su nombramiento como inquisidores ${ }^{68}$.

Insiste Zurita en la necesidad de proceder con el máximo cuidado en la elección de los oficiales del Santo Oficio, para evitar las críticas que la institución recibía por alguna de sus actuaciones. Pone como ejemplo el caso de las Inquisiciones de Sevilla y Granada al elegir como alguaciles a sobrinos y deudos de los inquisidores, sin consultar ni al Consejo ni al rey. Y lo que es peor, en el caso de Sevilla, se relevó en la vara de alguacil a un caballero honrado que llevaba muchos años en el cargo y a su sustituto se le «acreció el salario», algo que no se había hecho jamás ${ }^{69}$. El alguacil era un oficial

\footnotetext{
67. RAH, CSC, R/63, f. 127v.

68. AVILÉS FERNÁNDEZ, 1 (1984a): 78-84.

69. RAH, CSC, R/63, f. 128.
} 
ejecutivo encargado de las confiscaciones y la vara de su cargo, más larga que la de otros funcionarios inquisitoriales, como los secretarios, sobre los que tenía precedencia. Originariamente su salario era igual o incluso mayor que el de los inquisidores, ya que fue el responsable de la cárcel hasta $1515^{70}$.

Para evitar en lo posible los abusos y mantener la eficiencia de los tribunales, la Inquisición nombraba visitadores que debían encargarse de investigar su situación y funcionamiento de manera exhaustiva. Una vez hecha la investigación, tanto de actas, cárceles, administración y actuaciones de los oficiales y el inquisidor, el visitador redactaba un escrito recogiendo toda la información y la enviaba o llevaba personalmente a la Suprema. Dado que no solía tener autoridad ejecutiva, solo podía hacer recomendaciones sobre las medidas a adoptar ${ }^{71}$.

A juicio de Zurita no era suficiente que la visita del inquisidor «removioles y aun castigarlos con duros rigores», porque lo importante era que este tipo de elecciones no se produjeran. Y la forma de evitarlo era presentar al rey una nominación de las personas que concurrían a cada plaza, y así elegir a quien «sea de mejor cualidades». Además, debían continuar las visitas de los inquisidores sin ningún impedimento, aunque no hubiera ninguna queja, tal y como se había venido haciendo siempre y «vi muchas veces platicar entre los más antiguos que yo alcance». Finaliza el memorial con una última consideración sobre la necesidad de que el rey esté informado sobre la distribución de la hacienda, renta y bienes de la Inquisición ${ }^{72}$.

\section{El Inquisidor general ¿teólogo o jurista?}

El siguiente memorial está fechado el 24 de enero de 1573 y tiene como título: «Los inconvenientes que se presentan de ser teólogo el inquisidor general y no canonista o jurista son estos». Comienza explicando que ante dos candidatos con las mismas cualidades, uno teólogo y otro jurista, la elección sería más acertada con el segundo, porque en las causas de la fe estaría mejor preparado para juzgar. Lo cual estaba demostrado desde la fundación del Santo Oficio, dado lo peligroso que había resultado cuando habían sido teólogos quienes

70. LEA, 1982: 103.

71. Ibidem: 86-89.

72. RAH, CSC, R/63, f. 128.

Revista de Historia Moderna, n. ${ }^{\circ} 35$ (2017) (pp. 439-466) | ISSN-e: 1989-9823 | ISSN: 0212-5862 
habían dictado sentencias «muy exorbitantes, más miradas al rigor que a la clemencia». Además, continúa Zurita, cuando había habido un teólogo presidiendo el Consejo, los acuerdos habían sido más difíciles, por ser su voto opuesto al del resto de los miembros, o haber intentado imponer su parecer a los teólogos que formaban parte del mismo $^{73}$.

Ya hemos mencionado cómo los estudios universitarios eran comunes a todos los inquisidores generales de quienes tenía constancia Zurita. Pero la trayectoria académica «estuvo marcada por las necesidades de una institución cuyos cambios obligaban a modificar el cuadro de requisitos exigidos a los que pretendían formar parte de ella». La teología y los cánones eran imprescindibles para interpretar y resolver los casos, siendo Salamanca la universidad donde se graduó la mayoría de los que llegaron a ocupar el generalato inquisitorial hasta el siglo $\mathrm{XVI}^{74}$.

También entiende Zurita que, cuando hubiese en el Consejo algún teólogo, habría una continua diferencia en el voto por «una cierta confianza que los teólogos tienen de que aquel negocio es propio suyo y pueden votar más bien y mejor que los otros», y en cualquier tema, por grave e importante que fuera, intentarían imponer su voluntad.

Demás de esto, comúnmente son tenidos los teólogos por personas no tan aptas para el gobierno político, como sería necesario para el regimiento de las Inquisiciones. Y que [sí] lo son los juristas y canonistas, se ve por [la] experiencia en los Colegios y los Cabildos de la iglesia donde concurren de ambas profesiones ${ }^{75}$.

Continúa su exposición señalando que si el Consejo estuviese presidido por un inquisidor general teólogo, y los miembros fuesen canonistas o juristas, «habría necesariamente diversidad y diferencia entre la cabeza y los miembros» y el presidente no sería buen juez. El informe de Zurita sigue con un párrafo tachado en el que plantea el inconveniente que supone las diferencias entre teólogos que defienden las propuestas de santo Tomás o las de Scoto. Así, en caso de ser elegido como inquisidor general un seguidor de una de estas propuestas, estaría en contra de quienes estuvieran a favor de la

73. Ibidem, f. 131.

74. SÁNCHEZ RIVILLA, 1993: 720.

75. RAH; CSC, R/63, f. 131v.

Revista de Historia Moderna, n. ${ }^{\circ} 35$ (2017) (pp. 439-466) | ISSN-e: 1989-9823 | ISSN: 0212-5862 
otra. Este problema no existiría en caso de un canonista o jurista ${ }^{76}$. Repite, ampliando la explicación, lo expuesto en párrafos anteriores.

Zurita plantea de esta forma la discrepancia entre la ideología religiosa de los «ebolistas» y los «albistas»: místicos o intelectuales. Los primeros eran defensores de los jesuitas y de una religiosidad caracterizada por la observancia, el recogimiento, la oración mental y una ascesis exigente de mortificación. Los segundos defendían una teología más intelectual «en consonancia con los márgenes de espiritualidad seguidos por la Orden de Santo Domingo ${ }^{77}$. Estas prácticas místicas no resultaban adecuadas en un momento de intransigencia religiosa defendida por Valdés, que acusó a muchos miembros del partido «ebolista» de tener concomitancias con las ideas de Lutero ${ }^{78}$. Un ejemplo de hasta qué punto estaba dividida la forma de vivir la religiosidad en esos momentos, lo encontramos en Ponce de León y Quiroga, ambos candidatos idóneos para Zurita, ambos «ebolistas» o «papistas», pero enemigo declarado de los jesuitas el primero y defensor de la Compañía, el segundo ${ }^{79}$.

Así mismo, sigue exponiendo Zurita, «es de advertir que estando pendiente la causa del Arzobispo de Toledo», sirve como ejemplo que ningún teólogo ha dejado de expresar su opinión sobre el caso, sobre los libros y escritos de un prelado tan grande, y con quien habrán tratado y consultado. Y puesto que el inquisidor general no es juez ni tiene voto en esta causa, sería un inconveniente que fuese teólogo y quisiese dar su parecer y opinión a su Santidad. «Porque cuánta más cautela y prudencia tenían canonistas y juristas en los negocios que han de terminar». Como ejemplo de lo dicho pone a los dos papas que han llevado la causa contra Carranza, Pio V y Gregorio XIII, teólogo y jurista, respectivamente. Defiende al segundo por actuar «con más prudencia y más cautamente», además de que en «semejantes negocios se pueden seguir muy notables inconvenientes, como es notorio» ${ }^{80}$.

El proceso a Carranza y dos de sus principales protagonistas sirve para ver ambas formas de entender la política religiosa en ese periodo. El arzobispo de Toledo era partidario de «una cultura más próxima al humanismo

76. Ibidem.

77. PizARro Llorente, 1992: 229.

78. MARTínez Millán, 1994: 21.

79. PizarRo Llorente, 2004: 228 (nota 55).

80. RAH, CSC, R/63, f. 132. 
y una política más transigente en relación con los rebeldes flamencos ${ }^{81}$, mientras que Valdés persiguió cualquier asomo de heterodoxia religiosa. Sin olvidar que la persecución contra Carranza y los focos luteranos surgidos a mediados de siglo, sirvieron de excusa para que Valdés pudiese seguir en la Corte, manteniendo de esa forma su poder ${ }^{82}$. Cuando Zurita plantea la causa contra el arzobispo de Toledo en su memorial, lo hace, probablemente, por la repercusión de la misma. También tenía conocimiento directo del proceso, por la documentación que había manejado desde que inició su trabajo como secretario del rey ${ }^{83}$.

Las discrepancias entre Carranza y Valdés se extendían a lo que pensaban sobre la conveniencia o no de que fueran juristas o teólogos los miembros del Consejo de la Inquisición. Carranza era de la opinión de que debían ser teólogos y Valdés, letrados. Esta disparidad de criterios también la encontramos en Carlos V, partidario de los teólogos, y Felipe II, de lo contrario, aunque «la opinión e influencia de su familia (sobre todo la de su hermana, la princesa Juana) $[. .$.$] a veces le hizo seguir las ideas del partido ebolista» { }^{84}$.

Finalmente, sigue el memorial, los canonistas y juristas no se entrometían en lo que era propio de los teólogos. De la misma forma que no pretenderían presidir un consejo de teólogos, de no ser muy doctos en esa materia, sería inconveniente que un teólogo presidiese un consejo de canonistas. Tras estas consideraciones, Zurita no duda en reconocer los méritos de inquisidores generales que eran teólogos, y ejercieron con acierto su cargo, como el prior de Santa Cruz. O canonistas como fray Francisco Jiménez de Cisneros ${ }^{85}$.

81. MARTínez Millán, 1994: 29.

82. El rey pretendía que se trasladase a Sevilla para atender su arzobispado. MARTíNEZ Millán, 1992: 171.

83. También prepara las minutas de las cartas de Quiroga a Gregorio XIII referidas al proceso desde el 25 de noviembre de 1573 al 22 de junio de 1574 . PIZARRO LLORENTE, 2004: 366. Continuó manejando información referida a dicho proceso hasta después de la muerte de Carranza en Roma en 1576. EXTRAVÍS HERNÁNDEZ, 2014: 82-83.

84. MARTíNEZ MiLláN, 1992: 160 (nota 112).

85. RAH, CSC, R/63, f. 132v. 


\section{Sobre la mudança del Consejo}

Con este epígrafe iniciaba en 1572 Zurita un memorial para Felipe II sobre el lugar de reunión del Consejo de la Inquisición. En él hace un repaso de los diferentes lugares que ha utilizado este organismo desde su creación por los Reyes Católicos:

El Consejo de V. Md. de la General Inquisición, siempre que el inquisidor general residió en la Corte, se reunió y continuó en su posada y esto se sabe de los inquisidores generales pasados desde el cardenal Francisco Ximénez hasta el cardenal don Diego de Espinosa. Por ausencia de ellos larga o por su fallecimiento, siempre los del Consejo acostumbran a juntar en monasterios o iglesias, o en las casas de la Inquisición, si acaso se hallara la Corte en ciudad o villa adonde residiese el Santo Oficio de asiento ${ }^{86}$.

De esta forma el Consejo se reunió durante cuatro años (1534-1538) en casa del cardenal don Alonso Manrique, arzobispo de Sevilla, hasta su muerte. Después se trasladaron al monasterio de san Pedro Mártir, en Toledo, cuando la Corte se instaló en esa ciudad. Zurita le recuerda al rey que esta forma de actuar no «parecía tan indecente» ya que ocurría algo semejante con los Consejos de Indias, Hacienda o el de la Emperatriz. «Pero ahora que todos se reúnen en palacio por orden de V. Md., se echan mucho de ver, y algunos piensan que no es Consejo de V. Md. sino privado, siendo como los otros y librado como ellos por signo y sello Real de Cancillería» ${ }^{87}$.

El Consejo se reunía siempre en la Corte, aunque cuando esta era itinerante, buscaba una residencia estable que solía coincidir con la del inquisidor general. El aposentador real se ponía de acuerdo con el del Consejo para buscar un alojamiento que pudiese tener las garantías suficientes como para mantener el secreto del Santo Oficio. Más tarde, ya en el siglo XVII, la Suprema compró las casa de don Rodrigo Calderón para habilitarlas como sede estable del Consejo y sus archivos ${ }^{88}$.

Otro inconveniente que señala Zurita es la dificultad de tratar «causas muy graves» en las que concurren otros Consejos, además del de la Inquisición, si estos tienen lugares diferentes de reunión. La ventaja más importante, «para

86. Ibidem, f. 121.

87. Ibidem.

88. MESEGUER FERNÁNDEZ, 1984: 373 y 409. 
mayor beneficio de las causas de la fe», si las reuniones se realizaran en palacio, sería que el inquisidor general asistiese de ordinario a los Consejos. De esta forma se conseguiría «la buena y breve expedición de los negocios» y solo por una causa mayor suspendería su asistencia. En el supuesto de estar tan «impedido de vejez o enfermedad o otra ocupación como lo estuvieron por largo tiempo el Prior de Santa Cruz -primer inquisidor general-, el cardenal Adriano y el arzobispo don Hernando de Valdés», podría nombrarse a otro presidente del Consejo o un coadjutor ${ }^{89}$.

Todas estas consideraciones suponen que trasladar a palacio la sede del Consejo de la Inquisición no carezca de fundamento, señala Zurita en su memorial. Por tanto, la mudanza estaría hecha con «la consideración que V. Md. ordena y dispone las otras cosas de su estado» y mucho más en unos tiempos en los que «conviene que este Santo Oficio sea mirado y favoreciendo en todo aquello que fuere justo y honesto $»^{90}$. Dado que ha aumentado el número de oficiales de la Inquisición, y habiéndose asentado en Nueva España y Perú, «[...] se ha manifestado al mundo el santo celo de V. Md. y que tiene especial cuenta y cuidado sobre todas las cosas de su estado real y con las de nuestra santa fe católica y con el ensalzamiento y aumento de ella, de donde ha de estribar el fundamento del Imperio y el señorío temporal».

Zurita añade que siendo el de la Inquisición un Consejo más antiguo que los de Indias, Italia, Órdenes, Hacienda y Contadurías, parecería un «disfavor tenerle fuera de su lugar y del que tienen los otros ${ }^{91}$. Se debería tener en cuenta, además, que a diferencia de lo que ocurre en el Consejo de Italia o el de Aragón, en los que puede haber extranjeros, en el de la Inquisición solo los hay naturales y personas de gran dignidad.

El memorial termina con una última consideración a favor de instalar el Consejo del Santo Oficio en palacio: que dándose el caso de elegir como inquisidor general a «una persona de tanta autoridad y de tales partes, que pareciese no ocupar perlado y en ese caso, sería cosa más razonable hallarse

89. RAH, CSC, R/63, f. $121 \mathrm{v}$.

90. Ibidem.

91. Ibidem, f. 122. 
el consejo y tenerse en palacio y no residir en su posada, siendo como es Consejo de V. Md.» ${ }^{92}$.

Aunque las razones expuestas por Zurita al rey referentes a la instalación del Consejo de la Suprema en palacio no favorecieron dicho cambio, las relativas al nombramiento de nuevo inquisidor general parece que sí. Ya hemos visto lo ocurrido con la elección de Ponce de León y la valoración que de él había hecho Zurita ante el rey. En el caso de Quiroga, Henar Pizarro en la biografía de este inquisidor general, considera que la decisión de Felipe II estuvo influenciada por la información aportada por Zurita. «Buen conocedor de la Monarquía, Zurita avalaba ante el monarca la figura de Quiroga señalando la importancia que revestía el poder contar con una persona que tenía experiencia tanto en los Consejos de Castilla y de la Inquisición, siendo un perfecto conocedor de la Curia romana, donde además mantenía excelentes relaciones ${ }^{93}$.

\section{Conclusiones}

Tras el estudio de estos memoriales, sería aventurado plantear como un hecho probado la influencia de Zurita en la decisión de Felipe II al elegir inquisidor general tras la muerte de Espinosa, o situarle en uno de los dos grupos que se disputaban el poder en la Corte.

De sus relaciones personales con Ponce y Quiroga queda constancia en la correspondencia mantenida con ambos, principalmente referidas a su papel como historiador. Sobre el peso que su opinión pudo haber ejercido sobre el monarca a la hora de la elección de ambos como inquisidores generales, solo nos constan los billetes y memoriales dirigidos al rey con los consejos de Zurita, y el posterior trato favorable de Quiroga ante las peticiones de traspaso del cargo de secretario para su hijo Jerónimo. Pero teniendo en cuenta que Quiroga formaba parte del partido "papista», y el otro candidato al cargo era Mateo Vázquez, claro exponente del partido castellanista, quizás el apoyo a Zurita buscaba más evitar un enemigo en ese puesto, que agradecerle un hipotético favor.

92. Ibidem.

93. PizARro Llorente, 2004: 229.

Revista de Historia Moderna, n. 35 (2017) (pp. 439-466) | ISSN-e: 1989-9823 | ISSN: 0212-5862 
No obstante, si podemos plantear algunos hechos como ciertos. Zurita contaba con la confianza del rey para preparar informes relativos al funcionamiento del Santo Oficio. Estos memoriales contienen información fidedigna de la institución, desde su origen hasta el momento en que se preparan. Junto a los datos que podemos denominar históricos, Zurita añade opiniones propias sobre el asunto a tratar, justificándolas con ejemplos. También podemos encontrar juicios de valor, tanto positivos como negativos, de algunos inquisidores generales, especialmente de Manrique y Valdés, respectivamente.

Es especialmente crítico con los teólogos como inquisidores generales. Una posición que puede estar basada, quizás, en la actuación represora de Valdés en la causa contra Carranza y otras figuras relevantes de la cultura. Esta opinión desfavorable queda patente en la crítica que hace a la actuación de este inquisidor general a la hora de elegir a los oficiales del Santo Oficio durante su mandato. ¿Podría influir en este juicio su relevo como secretario en 1548? Aunque fue nombrado contador poco después, Zurita se quejaba porque su salario en este cargo era menor que el de su antecesor. En cualquier caso, esta opinión negativa sobre la actuación de Valdés está basada en hechos probados. Podríamos decir que, al igual que seguía el método científico basado en la crítica histórica de los documentos para escribir su obra histórica, actuaba de forma similar a la hora de seleccionar la información que trasmitía al rey en sus memoriales.

El debate sobre la conveniencia de que los inquisidores generales fueran teólogos o juristas estaba muy extendido y en él participaban, como hemos visto, desde el rey hasta destacados miembros de la Iglesia, la cultura o la política. En este caso la opinión de Zurita se fundamenta en situaciones ya ocurridas: la Historia entendida como magister vitae, confluyendo así su experiencia como historiador y oficial al servicio de la Corona.

En resumen, esta documentación nos sitúa en un periodo de cambios en los estamentos de poder de la Corte, con tensiones por la actuación de la Inquisición y con Zurita desempeñando un cargo que le permitía obtener información de primera mano de gran valor, parte de la cual transmitió a Felipe II en memoriales y notas. Gracias a ella, podemos conocer las tensiones políticas y religiosas del momento, vistas por un personaje que fue testigo privilegiado y, algunas veces, partícipe de las mismas. 


\section{Bibliografía}

Andrés de UztÁrroz, Juan F. y Dormer, Diego J., Progresos de la Historia de Aragón y elogios de Gerónimo Zurita, su primer cronista, Zaragoza, Diputación Provincial, 1878.

ANDRÉS MARTíN, M, «La consolidación del Santo Oficio (1517-1569)» en Joaquín Pérez Villanueva y Bartolomé Escandell Bonet (coord.), Historia de la Inquisición en España y América, I, Madrid, Centro de Estudios Inquisitoriales, 1984: 520-538.

AVILÉS FERNÁNDEZ, Miguel, «Los Inquisidores generales: estudio del alto funcionariado inquisitorial en los siglos XV y XVI», Ifigea: Revista de la Sección de Geografía e Historia, 1 (1984a): 77-91.

AVILÉS FERNÁNDEZ, Miguel, «La consolidación del Santo Oficio (1517-1569)», en Joaquín Pérez Villanueva y Bartolomé Escandell Bonet (coord.), Historia de la Inquisición en España y América, I, Madrid, Centro de Estudios Inquisitoriales, 1984b: 443-473, 599-612.

BARRIOS PINTADO, Feliciano, «Las competencias privativas del Inquisidor General en la normativa regia de los siglos XVI y XVII. Una aproximación al tema», Revista de la Inquisición, 1 (1991): 121-140. Disponible en: http://revistas. ucm.es/index.php/RVIN/article/view/RVIN9191110121A

CANELlas LóPEZ, Ángel, «El testamento de Jerónimo Zurita y otros documentos a él relativos», Universidad, X (1933): 1-22.

Domingo Malvedí, Arantxa, Disponiendo anaqueles para libros. Nuevos datos sobre la biblioteca de Jerónimo Zurita, Zaragoza, Institución Fernando el Católico, 2010.

EsCandell Bonet, Bartolomé, «La consolidación del Santo Oficio (15171569)» en Joaquín Pérez Villanueva y Bartolomé Escandell Bonet (coord.), Historia de la Inquisición en España y América, I, Madrid, Centro de Estudios Inquisitoriales, 1984: 434-442.

ESCUDERO, José Antonio, «Conflictos en el régimen funcionarial del Santo Oficio: los secretarios del Consejo», Historia. Instituciones. Documentos, 14 (1987): 75-84. Disponible en: http://institucional.us.es/revistas/historia/14/07\%20 escudero\%20lopez.pdf

EXTRAVÍs HERNÁNDEZ, Isabel, Jerónimo Zurita (1512-1580). Un esbozo biográfico, Zaragoza, Institución Fernando el Católico, 2014.

GARCíA CÁRCEL, Ricardo, «El periodo fundacional (1478-1517)», en Joaquín Pérez Villanueva y Bartolomé Escandell Bonet (coord.), Historia de la Inquisición 
en España y América, I, Madrid, Centro de Estudios Inquisitoriales, 1984: 405-426.

García CÁrCel, Ricardo y Moreno Martínez, Doris, Inquisición. Historia crítica, Madrid, Temas de hoy, 2000.

GonZÁlez Novalín, José Luis, «La consolidación del Santo Oficio (15171569)», en Joaquín Pérez Villanueva y Bartolomé Escandell Bonet (coord.), Historia de la Inquisición en España y América, I, Madrid, Centro de Estudios Inquisitoriales, 1984: 538-555, 613-647.

KAGAN, Richard L., «El cronista oficial ¿historiador o consejero?», Jerónimo Zurita, 88 (2013):199-210. Disponible en: http://ifc.dpz.es/recursos/publicaciones/33/63/09kagan.pdf

LEA, Henry C., Historia de la Inquisición española, II, Madrid, Fundación Universitaria Española, 1982.

LóPEz Vela, Roberto, «Las estructuras administrativas del Santo Oficio» en Joaquín Pérez Villanueva y Bartolomé Escandell Bonet (coord.), Historia de la Inquisición en España y América, II, Madrid, Centro de Estudios Inquisitoriales, 1993a: 63-274.

LÓPEZ VELA, Roberto, «Las estructuras sociales de la Inquisición» en Joaquín Pérez Villanueva y Bartolomé Escandell Bonet (coord.), Historia de la Inquisición en España y América, II, Madrid, Centro de Estudios Inquisitoriales, 1993b: 669-840.

MARTíneZ Millán, José, «Grupos de poder en la corte durante el reinado de Felipe II: la facción ebolista, 1554-1573», en José Martínez Millán (coord.), Instituciones y élites de poder en la monarquía hispana durante el siglo XVI, Madrid, Universidad Autónoma, 1992: 137-197.

Martínez Millán, José, «Estructura de la Hacienda de la Inquisición», en Joaquín Pérez Villanueva y Bartolomé Escandell Bonet (coord.), Historia de la Inquisición en España y América, II, Madrid, Centro de Estudios Inquisitoriales, 1993: 885-1076.

MarTínez Millán, José, «Introducción» en José Martínez Millán (coord.), La corte de Felipe II, Madrid, Alianza, 1994: 13-36.

MESEGUER FERNÁNDEZ, Juan, «El periodo fundacional (1478-1517)» en Joaquín Pérez Villanueva y Bartolomé Escandell Bonet (coord.), Historia de la Inquisición en España y América, I, Madrid, Centro de Estudios Inquisitoriales, 1984: 281-404. 
Pinto Crespo, V., «El apogeo del Santo Oficio (1569-1621)», en Joaquín Pérez Villanueva y Bartolomé Escandell Bonet (coord.), Historia de la Inquisición en España y América, I, Madrid, Centro de Estudios Inquisitoriales, 1984: 767-772.

PIZARRO LlORENTE, Henar, «Las relaciones de patronazgo a través de los inquisidores de Valladolid durante el siglo XVI», en José Martínez Millán (coord.), Instituciones y élites de poder en la monarquía hispana durante el siglo XVI, Madrid, Universidad Autónoma, 1992: 223-252.

PizarRo Llorente, Henar, Un gran patrón en la corte de Felipe II. Don Gaspar de Quiroga, Madrid, Universidad de Comillas, 2004.

REDONDO VEINTEMILLAS, Gregorio, «Jerónimo Zurita, primer cronista oficial de Aragón (1512-1580)», Jerónimo Zurita, 88 (2013): 11-46. Disponible en: http://ifc.dpz.es/recursos/publicaciones/33/63/02redondo.pdf

SAAVEDRA FAJARDO, Diego, Idea de un príncipe político-christiano, II, Valencia, Oficina de Salvador Faulí, 1801.

SÁNCHEZ RiviLla, Teresa, «Sociología de los inquisidores generales y Consejeros» en Joaquín Pérez Villanueva y Bartolomé Escandell Bonet (coord.), Historia de la Inquisición en España y América, II, Madrid, Centro de Estudios Inquisitoriales, 1993: 715-729.

SARASA SÁnchez, Esteban, «Los Anales de la Corona de Aragón de Jerónimo Zurita», Jerónimo Zurita, 88 (2013): 61-80. Disponible en: http://ifc.dpz.es/ recursos/publicaciones/33/63/04sarasa.pdf

Zurita, Jerónimo, Anales de Aragón, Ángel Canellas (ed.), José Javier Iso (coord.), María Isabel Yagüe y Pilar Rivero, 2003: http://ifc.dpz.es/publicaciones/ ebooks/id/2448, [consultado 15 enero de 2014]. 